\title{
Psychological maltreatment and its relationship with self-esteem and psychological stress among adolescents in Tanzania: a community based, cross-sectional study
}

\author{
Adela A. Mwakanyamale* and Yu Yizhen
}

\begin{abstract}
Background: Despite the growing recognition of childhood psychological maltreatment as a public health and human rights concern, it remains rampant in developing countries including Tanzania and has a negative impact on the victim's self-esteem during adolescence. There is a lack of published studies in Tanzania that examine the relationship between childhood psychological maltreatment and self-esteem during adolescence. This study describes the relationship between childhood psychological maltreatment and self-esteem and psychological distress among adolescents in Tanzania.

Methods: This was a cross-sectional, community-based study of secondary school students that was conducted in randomly selected secondary schools in five regions in Tanzania between April 2016 and February 2017. A multistage cluster sampling technique was employed to obtain the required number of study participants. The Rosenberg self-esteem scale, Kessler psychological distress scale (K10) and Childhood Trauma Questionnaire (CTQ) questionnaires were used to measure the variables in the study. Pearson correlation analysis was used to analyse the correlation between variables (Psychological maltreatment and self-esteem and psychological distress).

Results: A sample of 1000 secondary school students was recruited for this study, of which 553 (55.3\%) were males and 447 (44.7\%) were females. The mean age at presentation was $16.45 \pm 6.42$ years. Out of the 1000 participants, 766 (76.6\%) experienced psychological maltreatment. Emotional abuse was reported in $24.7 \%$ of the participants, while emotional neglect was reported in $51.9 \%$ of cases. There was a strong positive correlation between psychological maltreatment and self-esteem $(r=0.55, p<0.001)$, whereas the correlation between psychological maltreatment and psychological distress was significantly but weak ( $r=-0.086, p=0.007)$. The results also show a strong positive correlation between psychological distress and self-esteem $(r=0.16, p<0.001)$.

Conclusion: Finding from this study demonstrated that childhood psychological maltreatment is prevalent in our setting and is associated with psychological distress and low self-esteem during adolescence. Urgent intervention targeting at reducing occurrence of childhood psychological maltreatment is necessary to reduce the incidence of low self-esteem and psychological distress among Tanzanian adolescents.
\end{abstract}

Keywords: Psychological maltreatment, Self-esteem, Psychological distress, Adolescents, Tanzania

\footnotetext{
* Correspondence: ademwaka@yahoo.com

Department of surgical and medical nursing, Hubert Kairuki Memorial

University, Dar es salaam P.o Box 65300, Tanzania
}

(c) The Author(s). 2019 Open Access This article is distributed under the terms of the Creative Commons Attribution 4.0 International License (http://creativecommons.org/licenses/by/4.0/), which permits unrestricted use, distribution, and reproduction in any medium, provided you give appropriate credit to the original author(s) and the source, provide a link to the Creative Commons license, and indicate if changes were made. The Creative Commons Public Domain Dedication waiver (http://creativecommons.org/publicdomain/zero/1.0/) applies to the data made available in this article, unless otherwise stated. 


\section{Background}

Psychological maltreatment is the most prevalent form of child abuse and is increasingly recognized as an essential component of child maltreatment and the unifying concept that connects cognitive, affective, and interpersonal problems related to physical abuse, sexual abuse, and neglect [1]. Psychological maltreatment involves repeated interactions between a parent and child that are often verbal in nature that negatively affect the emotional, social, cognitive or even physical development of a child [2]. These interactions typically include acts of commission as well as omission, such as spurning, terrorizing, isolating, exploiting and denying emotional responsiveness [3].

Psychological maltreatment is believed to negatively affect the emotional, social and cognitive development of a child, making them more prone to substance abuse and other forms of psychopathology [4]. Psychological maltreatment is thought to be the most common form of maltreatment and encompasses both emotional abuses as well as emotional neglect and also tends to accompany other forms of maltreatment, such as physical and sexual abuse [5].

Emotional abuse refers to verbal assaults on a child's sense of worth or well-being, or any humiliating, demeaning, or threatening behaviour directed toward a child by an older person [6].

Emotional neglect is defined as failure of caretakers to provide a child's basic psychological and emotional needs, such as love, encouragement, belonging and support [7]. Emotional abuse can hurt to the same amount as physical abuse as it is not easy to identify, given that its effect may not be seen physically since the marks are on the inside instead of the outside [7] .It is commonly understood that there exist a few well designed and approved measures of childhood emotional abuse. Children with emotional child abuse become extremely loyal to their parents because of the fear of being punished in cases where they report abuse or think that this type of abuse or have a feeling that this is part of the normal way of life [8].

Indications of emotionally abused child include unsuitable way of behaving that may be associated with actions showing immaturity or more mature in relations to the child's age [9]. Overall change in behavior distraction of activities, clinging or impulsively seeking affection and attention forcefulness, unsupportiveness, bedwetting or loss of ability for bowel control (after a child has been trained), and damaging or disruptive behavior, constantly being sad and withdrawn) [10]. Moreover, this may also be indicated with poor relationships with age group peers, lacking of self-confidence and self-assurance, uncommon fears for the child's age such as fear of going home, being left alone, specific objects, or inability to react with emotion or develop an emotional bond with others, are also indicators. It is important to understand that any of the above behaviors may also be seen in normal children, but a change in pattern of these behaviors is a strong indicator of emotional abuse [11]. Emotional abuse and physical abuse may occur and may be induced by the same reasons, parents may become susceptible to being involved in the maltreatment in cases where stress in their lives have circumstances associated with stress in their lives or stress levels that are way up beyond their control [12].

Such dispositions in parents may lead to decreased capacity for consideration and handling of their children affairs as expected of them which may result in slowed mental growth or mental retardation, psychopathology, alcoholism, drug abuse and unrealistic ideas about their children's needs or sadistic psychosis [13].

It also occurs that the abuser's goal may be to control. Nevertheless, a single factor may not lead to abuse, but a collection of many factors may lead to creation of social and emotional burdens that may result in emotional abuse [14].

The known types of problems that can contribute to emotional abuse by parents may be related to social problems that can result in family stress such as joblessness, scarcity or poverty, segregation from relatives and friends, separation, death, adolescent parents, health crises, illness of a family member, incapacity of one of the family members or even drug and alcohol abuse within the family and mental health problems (mental incapacity, depression) [15].

The implications of emotional child abuse can be grave and long-standing. A number of research studies have concluded that psychopathologic signs are more likely to result in children who are emotionally abused. As a result, children with this effect may experience long-term depression, disaffection, anxiety, low self-esteem and unstable relationships or failure to show empathy to their counterparts [16]. During their childhood, victims of abuse may fail to flourish or their growing progress may be halted or slowed. Some may find it difficult to adjust emotionally and psychologically [17].

Some adolescents often find it difficult to trust, participate and a get the happiness in their relationships with others as a result of the abuse during childhood. Later in adulthood they may have trouble knowing and appreciating the needs and feelings of their own children and end up emotionally abusing them as well [18].

Emotional Neglect comes as a result of a parent's inability to respond well enough to a child's emotional needs, sometimes associated to mistreatment and abuse. Whereas mistreatment and abuse are parental acts, emotional neglect is a parent's failure to act. It's a failure and sometimes inability to notice, attend to, or responds appropriately to a child's feelings. Given that it is an act of omission, it's not easily visible, noticeable or memorable [19]. 
Neglect is the white space in the family picture, the background rather than the foreground. As much as it is often overlooked it does silent harm and damage to the concerned children [20]. Emotionally neglected children in turn grow up to a set of struggles. Since their emotions were not made valid by their parents in adulthood, they are likely to face a struggle identifying their own emotions. Understanding their own feelings as well as those of others may even be more difficult, this is because an important part of themselves and their emotional self has been denied and this may lead to a feeling of disconnect, unfulfillment or emptiness [21]. Trusting and relying upon others becomes even difficult to them, sometimes they may have a feeling of being different from others and a feeling that something that is wrong but do not know what it is that is wrong [22].

In another way parents can emotionally neglect their children without knowing what damage they are causing to their children. Being neglected may lead to struggle with self-disciplines in adulthood.

It occurs that at the end, most often during adulthood those who experienced neglect do not have the childhood memories and therefore their difficulties are blamed on themselves rather than on their parents' failures [23].

Today emotional neglect has been ignored. This is because it's not easily noticed and cannot be recalled by its victims. It has in many ways been overshadowed by the more visible childhood events, such as abuse and trauma [23].

Emotional abuse and neglect have been reported to cause significant harm to the child's development, and this harm extends into adolescence and adult life [24]. Unlike cases involving physical or sexual abuse, emotional abuse and neglect are believed to be the least likely to be reported by victims; victims are rarely able to demonstrate visible proof and therefore lack a sense of legitimacy [25]. Meta-analyses on the prevalence of different types of maltreatment have reported $17.7 \%$ for physical abuse, $26.7 \%$ for psychological abuse, $11.8 \%$ for sexual abuse and $16.3 \%$ for neglect [26].

Globally, the prevalence of psychological maltreatment has been estimated to be $36 \%$ of children [26]. One study in Turkey found that approximately $51 \%$ of children were psychologically maltreated [27]. According to agency reports, the prevalence of psychological maltreatment in England, the USA and Canada ranged from 11 to $34 \%$ [28]. A high prevalence ranging from 31.3 to $68.5 \%$ has been reported in East Asia and the Pacific Region [29].

Previous studies e.g., [30, 31] have reported a strong positive correlation between psychological maltreatment and low self-esteem.

This correlation between low self-esteem and psychological maltreatment is derived by the fact that psychological maltreatment in children can negatively affect the cognitive, social and emotional development of a child.

Self-esteem can be explained as continued self-evaluation and self-belief that one is strong, worthy, famous and successful [32]. Individuals with high self-esteem feel quite positive about their characteristics and competencies, which can positively influence well-being, while low self-esteem can lead to many emotional and behavioural problems [33].

Many studies have also evaluated the relationship between self-esteem and emotional and behavioural problems [34] . Findings from these studies suggest that individuals with more emotional and behavioural problems have lower self-esteem. Parents play a keyhole in the development of self-esteem, which reflects individuals' evaluations of themselves and their competencies [35]. Psychological maltreatment experiences include parental acts that negatively affect mental health and development [36]. Psychological maltreatment is also associated with psychological distress, which is largely defined as a state of emotional suffering characterized by symptoms of depression (e.g., lost interest; sadness; hopelessness) and anxiety (e.g., restlessness; feeling tense) [37]. Psychological distress is reported to be an indicator of the mental health of the population in public health [38].

The psychological maltreatment of children is widespread in developing countries including Tanzania and is believed to affect the overall psychological adjustment of the child [10]. As a result, victims may experience psychological distress, with symptoms of low self-esteem, depression and anxiety that may result in substance abuse [39].

However, it has been suggested that in a cultural environment where harsh disciplining techniques are accepted, the adverse impact on recipients may be minimal [40].

Studies conducted in sub-Saharan countries have reported that many children are exposed to high levels of psychological maltreatment [41]. Experiences from Tanzania show that parents often employ harsh physical and emotional discipline practices and believe that they do not harm their children [42].

Several studies conducted in most developing countries show a strong relationship between exposure to psychological maltreatment and low self-esteem [43]. Psychological maltreatment, including emotional abuse and neglect, is extremely common in Tanzania, yet not as broadly researched as sexual and physical abuse [44].

Decades of research on psychological maltreatment in childhood have resulted in publications on the subject in the developed countries, especially the U.S. and Europe. To our knowledge, no research or publication has been done on the relationship between psychological maltreatment and self-esteem in childhood in many developing 
countries. Studies have shown that witnessing domestic violence has a negative impact on a child's well-being and healthy development, especially in relation to psychological aspects such as low self-esteem [45].

This study aims to cover that knowledge gap and address the relationship between self-esteem and psychological maltreatment in childhood in developing countries. We conducted our study in five different cities in Tanzania, East Africa.

\section{Methods}

\section{Study design}

A cross-sectional, community-based study was conducted at randomly selected secondary schools in Tanzania between April 2016 and February 2017.

\section{Study participants}

Approximately 1115 secondary school students received the questionnaires and were asked to return the completed questionnaires in sealed envelopes. A total of 1000 secondary students returned the completed materials (89.7\% response rate), of which 553 (55.3\%) were male and $447(44.7 \%)$ were female, as shown in Table 1 . The participants' ages ranged between 13 and 21 years old.

\section{Measures}

The Rosenberg self-esteem scale, Kessler psychological distress scale (K10) and Childhood Trauma Questionnaire were used to measure the variables in this study.

Childhood self-esteem was assessed using the Rosenberg Scale, a 10-item scale. Self-esteem can be defined as positive and negative feelings about oneself. In the Rosenberg Self-Esteem Scale [46], high scores are indicative of positive self-regard, while the lower scores indicate negative self-regard. We also used a 4-point Likert scale to rate the Rosenberg Self-Esteem items $(1=$ strongly agree, and $4=$ strongly disagree). The final scores were determined by summing all the ratings from the Likert scale. A final score between 15 and 20 was indicative of normal self-esteem, a final score $<15$ indicate low self-esteem, while a final score $<25$ indicate high self-esteem. The Rosenberg Self-Esteem Scale is used to estimate self-esteem globally, with a high level of reliability and validity [46], and the scale has a test-retest correlation between 0.82 and 0.88 .

Table 1 Age group and gender distribution

\begin{tabular}{cllll}
\hline & \multicolumn{2}{l}{ Age of the participants } & Total \\
\cline { 2 - 4 } & $13-15$ & $16-18$ & $19-21$ & \\
\hline Gender & 211 & 282 & 60 & 553 \\
Male & 83 & 259 & 105 & 447 \\
Female & 294 & 541 & 165 & 1000 \\
Total & & & & \\
\hline
\end{tabular}

\section{The childhood trauma questionnaire (CTQ)}

The Childhood Trauma Questionnaire (CTQ) was established from a 70-item retrospective questionnaire in which participants were required to rate the frequency ( 0 - never true to 5- very often true) of abuse and neglect events that they had experienced during their childhood.

The CTQ was established by Bernstein and Fink. The CTQ is a self-reported inventory providing reliable and effective screening for a history of childhood neglect and abuse [47].

The CTQ is also appropriate for adolescents (age 12 and over) [48]. CTQ items assess exposure to 10 types of ACEs, including abuse (i.e., physical, emotional and sexual), neglect (i.e., emotional and physical), and household challenges (i.e., mental illness, substance abuse, physical violence, parental divorce and incarcerated family members) prior to age 18. Children are required to answer a series of statements regarding childhood life experience that are endorsed on a 5-point Likert scale according to their frequency [49].

The CTQ is psychometrically comprehensive in community samples, with the best test-retest reliability [50], displaying convergent and discriminant validity [50]. It has been demonstrated that the CTQ can display test-retest reliabilities between 0.79 and 0.86 and internal consistency reliability ranging from 0.66 to 0.92 [51].

For the purpose of this study, we used seven items in the CTQ questionnaire. The seven items focused on psychological maltreatment. Three of them measured emotional neglect, while the other four also assessed emotional abuse.

The Kessler Psychological Distress scale (K10) was developed in 1992 by Professors Kessler and Mroczek. It is globally used to measure non-specific psychological distress in the anxiety-depression spectrum. It was used in this study to assess psychological disorders, as most of these disorders are associated with anxiety and depressive symptoms [52]. The Kessler Psychological Distress scale has been used worldwide in WHO international studies and is also identified as a cross-cultural scale. A high score in the Kessler Scale is indicative of a psychological disorder [52].

The K10 comprises ten questions about psychological distress, and items are rated on a five-point ordinal scale. The total K10 score for each respondent was calculated by summing all 10 items, and scores ranged from 10 to 50 .

A score under 20 is considered normal (no stress), a score of 20-24 indicates a mild mental disorder (mild stress), a score of 25-29 indicates a moderate mental disorder (moderate stress), and a score of 30 and over indicates a severe mental disorder (severe stress) [52].

\section{Sampling technique}

A multistage cluster sampling technique was employed to obtain the required number of study participants. A 
sampling frame from the list of secondary school students from randomly selected secondary schools in five regions in Tanzania was prepared and used to draw up the sample. From the sampling frame, study units were sampled through the simple random method until the required sample was obtained.

\section{Study variables}

There were two major variables in the study, including independent and dependent variables. The independent variable represents psychological maltreatment, while self-esteem and psychological stress were treated as the dependent variables in this study.

\section{Statistical data analysis}

The statistical data analysis was performed using the Statistical Package for Social Sciences (SPSS) version 21.0 for Windows (SPSS, Chicago IL, USA). The descriptive and inferential statistics were calculated (mean $(\mathrm{M})$, $\mathrm{SD}=$ Standard deviation, $\mathrm{P}=p$-value) and ranges were calculated for continuous variables, whereas proportions and frequency tables were used to summarize categorical variables. Pearson correlation analysis was conducted to examine the relationship between variables, which describes the direction and strength of a relationship between two continuous or interval variables in our study, where the direction can be negative or positive.

In our study, psychological maltreatment was treated as a predictor variable, while both self-esteem and psychological stress was treated as dependent variables. A $p$-value of 0.001 was considered to be significant.

\section{Ethical consideration}

Ethical clearance was obtained from the review committee from the Huazhong University of Science and Technology, Tongji Medical College, China and the Ministry of Education in Tanzania. A formal letter was submitted to the respective educational district offices and subsequently to head teachers of secondary schools where the study was conducted. Written permission from the parents of the respondents was obtained a day before the time of data collection. Oral and written permission from the schools and the respective study subjects was obtained. The study was explained to the subjects. Its purpose and its confidentiality were explained, and the subjects' consent to participate in the study was assured before completing the questionnaire.

\section{Results}

\section{Social-demographic characteristics}

Out of the 1000 participants in the present study, 553 (55.3\%) were males and 447 (44.7\%) were females. The male-to-female ratio was 1.2:1. The ages of the participants at presentation ranged from 13 to 21 years with a mean of $16.45 \pm 6.42$ years. The majority of participants were in the age group of 16-18 years, accounting for $541(54.1 \%)$ cases (Table 1$)$.

Table 2 shows that out of the 1000 participants, 766 (76.6\%) experienced psychological maltreatment. Emotional abuse was reported in $24.7 \%$ of the participants, while emotional neglect was reported in $51.9 \%$ of cases. Comparing males and females, the prevalence of emotional abuse was higher in female participants (26.2\%) than their male $(23.5 \%)$ counterparts, while the prevalence of emotional neglect was higher among male participants (53.3\%) than female $(50.1 \%)$ participants. Regarding age group distribution, the prevalence of emotional abuse (30.5\%) and emotional neglect (55.8\%) was higher in the 19-21-year age group than the other age groups.

Table 3 shows severe psychological distress, reported in higher $71(54.6 \%)$ rate among female students than male 59(45.4\%). However, the difference was not statistically significant $P$-value $=0.072$.

The findings in Table 4 show a strong positive correlation between psychological maltreatment and self-esteem $(r=0.51, p<0.001)$, whereas the correlation between psychological maltreatment and psychological distress was significantly but weak $(r=-0.086, p=0.007)$. The results also show a strong positive correlation between psychological distress and self-esteem $(r=0.16, p<0.001)$.

Finally, the linear regression model (Table 5) was calculated to determine the impact of psychological maltreatment to both low self-esteem and psychological distress.

The regression result reveals that psychological maltreatment has a statistically significant impact on self-esteem, $R^{2}=.26, \beta=.515, \mathrm{~F}(1,998)=35.8, p<.01$.

Approximately $26 \%$ of the variance in self-esteem can be explained by psychological maltreatment. Moreover, psychological maltreatment has also a statistically significant impact on psychological distress $R^{2}=.007, \beta=-.086$, $\mathrm{F}(1,998)=7.36, p<.01$. This means that the value of $0.6 \%$ of the variance in psychological distress can be explained by one-unit change in psychological maltreatment.

Table 2 Prevalence of psychological maltreatment by gender and age group

\begin{tabular}{clll}
\hline & Total & $\begin{array}{l}\text { Emotional } \\
\text { abuse } \\
247(24.7 \%)\end{array}$ & $\begin{array}{l}\text { Emotional } \\
\text { neglect }\end{array}$ \\
\hline Age & 519(51.9\%) \\
$13-15$ & $294(29.4)$ & $66(22.4)$ & $144(49.0)$ \\
$16-18$ & $541(54.1)$ & $131(24.2)$ & $283(52.3)$ \\
$19-21$ & $165(16.4)$ & $50(30.5)$ & $92(55.8)$ \\
Gender & & $130(23.5)$ & $295(53.3)$ \\
Male & $553(55.3)$ & $117(26.2)$ & $224(50.1)$ \\
Female & $447(44.7)$ & & \\
\hline
\end{tabular}


Table 3 Prevalence of psychological distress by gender

\begin{tabular}{llll}
\hline $\begin{array}{llll}\text { Psychological } \\
\text { Distress }\end{array}$ & \multicolumn{2}{l}{ Sex N (\%) } & P-Value \\
\cline { 2 - 3 } & Male & Female & \\
\hline Normal & $332(56.0)$ & $261(44.0)$ & 0.072 \\
Mild & $105(59.3)$ & $72(40.7)$ & \\
Moderate & $59(59.0)$ & $41(41.0)$ & \\
Severe & $59(45.4)$ & $71(54.6)$ & \\
\hline
\end{tabular}

\section{Discussion}

Psychological maltreatment in children represents the most challenging and prevalent form of child abuse and neglect worldwide [53], but until recently, it has received relatively little attention in developing countries such as Tanzania. In this study, the presence of psychological maltreatment during childhood was reported in $76.6 \%$ of cases, emotional abuse was reported in $24.7 \%$ of the participants, while emotional neglect was reported in $51.9 \%$, which is comparable with that reported in developing countries [54] but higher than that observed in many other studies in developed countries [55]. The prevalence of psychological maltreatment in the present study may be underestimated because this form of child maltreatment is mostly underreported to authorities for fear of being arrested by the police. Also, psychological maltreatment is often not recognized when other forms of maltreatment, such as physical and sexual abuse, coexist [56]. The prevalence rates of psychological maltreatment may also be underestimated because they capture a wide range of parenting behaviours, and there is little to no consensus across studies as to what phenomena should be included [57].

Psychological maltreatment consists of both emotional abuse as well as emotional neglect $[58,59]$. In the present study, the prevalence of emotional neglect was higher among male participants than female participants, this finding agrees with what has previously been reported [60], emotional abuse was reported in $24.7 \%$ of the participants, while emotional neglect was reported in $51.9 \%$ of cases. The prevalence of emotional abuse was higher among female participants than their male counterparts.

Table 4 Correlation between psychological maltreatment, self-esteem and psychological distress

\begin{tabular}{lclcc}
\hline Variables & $M \pm S D$ & $\begin{array}{l}\text { Self- } \\
\text { esteem }\end{array}$ & $\begin{array}{l}\text { Psychological } \\
\text { distress }\end{array}$ & $\begin{array}{l}\text { Psychological } \\
\text { maltreatment }\end{array}$ \\
\hline Self-esteem & $27.6 \pm 4.2$ & 1.00 & & \\
$\begin{array}{l}\text { Psychological } \\
\text { distress }\end{array}$ & $24.6 \pm 4.5$ & $.164^{* *}$ & 1.00 & \\
$\begin{array}{l}\text { Psychological } \\
\text { maltreatment }\end{array}$ & $10.4 \pm 2.3$ & $.515^{* *}$ & $-.086^{* *}$ & 1.00 \\
${ }^{* *}$ Correlation is significant at the 0.01 level (2-tailed) \\
${ }^{* *} p<.001$. M: Mean, SD = Std Deviation, $N=1000$ (Number of participants)
\end{tabular}

Table 5 Linear regression analysis on self-esteem and psychological distress

\begin{tabular}{|c|c|c|c|}
\hline Variables & $\begin{array}{l}\text { Unstandardized } \\
\text { B }\end{array}$ & $\begin{array}{l}\text { Standardised } \\
\text { Coefficient Beta( } \beta)\end{array}$ & $\begin{array}{l}\text { Standard } \\
\text { Error }\end{array}$ \\
\hline \multicolumn{4}{|l|}{$\begin{array}{l}\text { Predicted variable } \\
\text { Self -esteem }\end{array}$} \\
\hline Intercept & $18.09^{* *}$ & & .516 \\
\hline $\begin{array}{l}\text { Psychological } \\
\text { Maltreatment }\end{array}$ & & $.515^{* *}$ & .50 \\
\hline R Square & .265 & & \\
\hline$F(1,998)$ & 359.89 & & \\
\hline \multicolumn{4}{|c|}{$\begin{array}{l}\text { Predicted variable: } \\
\text { Psychological distress }\end{array}$} \\
\hline Intercept & $26.34^{* *}$ & & \\
\hline $\begin{array}{l}\text { Psychological } \\
\text { Maltreatment }\end{array}$ & & $-.086^{* *}$ & .642 \\
\hline R Square & .007 & & .06 \\
\hline$F(1,998)$ & 7.36 & & \\
\hline
\end{tabular}

The reason for the underlying vulnerabilities and gender influence on children with emotional abuse and neglect is unclear, and this requires further investigation.

Although psychological maltreatment is the most common form of childhood maltreatment in developing countries such as Tanzania, no participants who were psychologically maltreated sought professional treatment. This observation may be attributed to the lack of awareness and poor knowledge regarding which childhood experiences constitute psychological maltreatment. This calls for urgent preventive measures to reduce the occurrence of childhood psychological maltreatment so as to reduce the potential adverse consequences of psychological maltreatment that occurs during adolescence and adulthood.

Psychological maltreatment is strongly associated with low self-esteem in adolescents [16]. This finding agrees with our study, which found that childhood psychological maltreatment was statistically significantly associated with self-esteem during adolescence. Parenting style plays a crucial role in a child's social, cognitive and emotional development. A negative parenting style involving psychological maltreatment may result in low self-esteem in adolescents that continues to adulthood [17].

The results reported here agree with previously published studies, demonstrating correlation between childhood exposure to psychological maltreatment and self-esteem. Children exposed to high levels of psychological maltreatment have been reported to show low level of self-esteem during adolescence. For a psychologically maltreated child, the negative impacts are believed to occur when the child internalizes the harsh treatment, including the negative messages from parents 
and/or care givers [18]. This results in insecurities, and the child develops maladaptive interpersonal schemas, which lead to dysfunctional behaviours [61].

Children in such situations tend to believe that they are worthless and that the world is unsafe and perceive everybody as abusive [19]. Those with low self-esteem tend to be more self-conscious and isolate themselves from others [62].

There are some limitations of the study that should be noted: first, the cross-sectional study design does not allow for the establishment of a causal relationship; therefore, only the association between psychological maltreatment and self-esteem was established in this study.

Second, the study participants included secondary school students from randomly selected secondary schools in five regions in Tanzania; therefore, the results cannot be generalized to the Tanzanian population as a whole. Third, additional consideration should be given to the tendency of participants to under- or over-report incidents of maltreatment. Thus, the results must be interpreted with caution.

\section{Conclusion}

The purpose of this study was to build upon the extant literature concerning childhood psychological maltreatment and its relationship to self-esteem and psychological distress. The results demonstrate that childhood psychological maltreatment is prevalent in our setting and is statistically significant because it causes the reduction of self-esteem among Tanzanian adolescents. Moreover, exposure to psychological maltreatment during childhood was found to be significantly weak associated with an increased likelihood of experiencing psychological distress in adolescence. The understanding of the interrelatedness of psychological maltreatment with self-esteem should be considered in the design of studies, treatments, and programs to prevent psychological maltreatment as well as low self-esteem.

Urgent preventive measures aiming at reducing the incidence of childhood psychological maltreatment is necessary to lessen the incidence of low self-esteem and psychological distress among Tanzanian adolescents. Strategic national educational programs should be implemented to bring awareness of the adverse effects of childhood psychological maltreatment. Parents, caregivers and teachers will benefit from realizing the effects of childhood psychological maltreatment and be encouraged to take an alternative method of discipline.

\section{Acknowledgements}

The authors are thankful to those who participated in the preparation of this manuscript. The authors acknowledge the help of the students who participated in this study and the teachers who delivered and collected questionnaires.
Funding

This study had no sources of funding. Authors met all operational costs.

\section{Availability of data and materials}

The datasets used and analyzed during the current study are available from the corresponding author on reasonable request.

\section{Authors' contributions}

AAM conceived the study, participated in study design, literature search, data analysis, manuscript writing and submission. YY contributed to the study design, data analysis and interpretation and manuscript editing Both authors read and approved the final manuscript.

\section{Ethics approval and consent to participate}

Before the commencement of the study, a letter of approval to conduct the study was sought by the authors and was provided by the Tongji Medical College, Huazhong University of Science and Technology institutional ethical review. Approval to conduct the research in secondary schools has been granted by Regional Administrative Secretary (RAS) of the respective regions in Tanzania. Permission has been granted by respective secondary school authorities.

Participants were informed about the purpose of the study, and they were assured that their answers would only be used anonymously for research purposes on a voluntary basis.

All participants aged 18 and above were given information about the study, and they were asked for their voluntary participation. A written informed consent was administered to each participant; all participants read and signed written consent forms before being enrolled in the study.

For students under 18 years old, consent (agreement to participate in study) was sought and obtained from their parents or guardians.

\section{Consent for publication}

Not applicable

\section{Competing interests}

The authors declare that they have no competing interests.

\section{Publisher's Note}

Springer Nature remains neutral with regard to jurisdictional claims in published maps and institutional affiliations.

Received: 20 June 2018 Accepted: 3 May 2019

Published online: 11 June 2019

\section{References}

1. Paul E, Eckenrode J. Childhood psychological maltreatment subtypes and adolescent depressive symptoms. Child Abuse Negl. 2015;47:38-47.

2. Higgins DJ, McCabe MP. Relationships between different types of maltreatment during childhood and adjustment in adulthood. Child Maltreat. 2000;5:261-72.

3. Arslan G. Psychological maltreatment, emotional and behavioral problems in adolescents: the mediating role of resilience and self-esteem. Child Abuse Negl. 2015;52:200-09.

4. Cosić I, BuljanFlander G, Karlović A. Correlation between childhood abuse and some aspects of psychological functioning of adolescents. Contemp SuvremPsihol. 2002;2:191-205.

5. Arslan G. Psychological maltreatment, emotional and behavioral problems in adolescents: the mediating role of resilience and self-esteem. Child Abuse Negl. 2016;52:200-9.

6. Allen B. An analysis of the impact of diverse forms of childhood psychological maltreatment on emotional adjustment in early adulthood. Child Maltreat. 2008;13(3):307-12

7. Ward H, Brown R. Assessing parental capacity to change when children are on the edge of care : an overview of current research evidence research report; 2014. p. 1-193.

8. World Health Organization. "Child abuse and neglect by parents and other caregivers," World Rep Violence Heal. 2002. p. 59-86.

9. Goldsmith RE, Freyd JJ. Awareness for emotional abuse. J Emot Abus. 2005; 5(1):95-123.

10. World Health Organization. Child abuse and neglect by parents and other caregivers, World Rep Violence Heal; 2002. p. 59-86. 
11. Shaffer A, Yates TM, Egeland BR. "The relation of emotional maltreatment to early adolescent competence: Developmental processes in a prospective study," Child Abuse Negl. 2009;33(1):36-44.

12. Glaser D. Emotional abuse and neglect (psychological maltreatment): a conceptual framework. Child Abuse Negl. 2002;26(6-7):697-714.

13. Kimber $\mathrm{M}$, et al. Consequences of child emotional abuse, emotional neglect and exposure to intimate partner violence for eating disorders : a systematic critical review; 2017. p. 1-18.

14. Taillieu TL, Brownridge DA, Sareen J, Afifi TO. Child abuse \& neglect childhood emotional maltreatment and mental disorders : results from a nationally representative adult sample from the United States. Child Abuse Negl. 2016;59:1-12.

15. Wilkinson J. The impacts of abuse and neglect on children ; and comparison of different placement options; 2017.

16. United Nations Children's Fund, Child maltreatment: prevalence, incidence and consequences in the East Asia and Pacific region: a systematic review of research. 2012.

17. Fry D, McCoy A, Swales D. The consequences of maltreatment on children's lives: a systematic review of data from the East Asia and Pacific region. Trauma Violence Abuse. 2012;13(4):209-33.

18. Gilbert R, Widom CS, Browne K, Fergusson D, Webb E, Janson S. Burden and consequences of child maltreatment in high-income countries. Lancet. 2009;373(9657):68-81.

19. Spertus IL, Yehuda R, Wong CM, Halligan S, Seremetis SV. Childhood emotional abuse and neglect as predictors of psychological and physical symptoms in women presenting to a primary care practice. Child Abuse Negl. 2003;27(11): 1247-58.

20. Cong E, et al. "Childhood sexual abuse and the risk for recurrent major depression in Chinese women." Psychol Med. 2012;42(2):409-17.

21. Neglect CE. Recovering from childhood emotional neglect four steps to putting yourself first; 2012. p. 845

22. Trickett PK, Kim K, Prindle J. "Child Abuse \& Neglect Variations in emotional abuse experiences among multiply maltreated young adolescents and relations with developmental outcomes" Child Abuse Negl. 2011;35(10):87686.

23. Demers LA, Rauch SL, Olson EA, Sonis LA, Jensen JE, Rosso IM. Childhood emotional neglect and trait resilience are related to ventromedial childhood emotional neglect and trait resilience are related to ventromedial prefrontal cortex volume in PTSD, vol. i; 2016.

24. Longman-Mills S, et al. Psychological maltreatment and its relationship with substance abuse among university students in Kingston, Jamaica maustratos psicológicos e sua relação com o abuso de substâncias entre estudantes universitários em Kingston, Jamaica. Artig Orig Texto Context Enferm. 2015;24:63-8.

25. Wright MO, Crawford E, Del Castillo D. Childhood emotional maltreatment and later psychological distress among college students: the mediating role of maladaptive schemas. Child Abuse Negl. 2009;33(1):59-68.

26. Stoltenborgh $M$, Bakermans-Kranenburg MJ, Alink LRA, van IJzendoorn $\mathrm{MH}$. The universality of childhood emotional abuse: a meta-analysis of worldwide prevalence. J Aggress Maltreat Trauma. 2012;21(8):870-90

27. Ozbas AA, Gurhan N, Kocak M. The relation of traumatic childhood experiences with psychological symptoms and self-esteem in physical education and sport students; 2013. p. 79-85.

28. Hibbard R, et al. Psychological maltreatment. Pediatrics. 2012;130(2):372-8,

29. Kwok SYCL, Yeung JWK, Low AYT, Lo HHM, Tam CHL. The roles of emotional competence and social problem-solving in the relationship between physical abuse and adolescent suicidal ideation in China. Child Abuse Negl. 2015;44:117-29.

30. Arata CM, Langhinrichsen-Rohling J, Bowers D, O'Brien N. Differential correlates of multi-type maltreatment among urban youth. Child Abuse Negl. 2007;31:393-415.31.

31. Benbenishty R, Zeira A, Astor RA. Children's reports of emotional, physical and sexual maltreatment by educational staff in Israel. Child Abuse Negl. 2002;26:763-82.

32. Mostafavi F, Azadbakht L, Daniali S. Relationship between body satisfaction with self esteemand unhealthy body weight management. Educ Health Promot. 2013;2(1):29.

33. Alshawi AF, Lafta RK. Relation between childhood experiences and adults self-esteem: A sample from Baghdad. Qatar Med J. 2014;2014:1-10.

34. Sesar K, Zivcić-Bećirević I, Sesar D. Multi-type maltreatment in childhood and psychological adjustment in adolescence: questionnaire study among adolescents in Western Herzegovina Canton. Croat Med J. 2008; 49:243-56.

35. Sesar K, Zivcic-Becirevic I, Sesar D. Multi-type maltreatment in childhood and psychological adjustment in adolescence: questionnaire study among adolescents in Western Herzegovina Canton. CMJ. 2008;49(2):243-56.

36. Edwards VJ, Holden GW, Felitti VJ, Anda RF. Relationship between multiple forms of childhood maltreatment and adult mental health in community respondents: results from the adverse childhood experiences study. Am J Psychiatry. 2003;160(8):1453-60.

37. Jarman $L$, et al. Prevalence and correlates of psychological distress in a large and diverse public sector workforce: baseline results from partnering healthy@work. BMC Public Health. 2014;14(1):125.

38. Goodwin R, Takahashi M, Sun S, Ben-Ezra M. Psychological distress among tsunami refugees from the great East Japan earthquake. Br J Psychiatry Open. 2015:1(1):92-7.

39. R. F. Anda et al., "Adverse childhood experiences and smoking during adolescence and adulthood," 2016.

40. Dube SR, Felitti VJ, Dong M, Chapman DP, Giles WH, Anda RF Childhood abuse, neglect, and household dysfunction and the risk of illicit drug use: the adverse childhood experiences study. Pediatrics. 2003:111(3):564-72.

41. Hermenau K, Eggert I, Landolt MA, Hecker T. Neglect and perceived stigmatization impact psychological distress of orphans in Tanzania. Eur J Psychotraumatol. 2015;6:1-9.

42. Barker G, et al. "the United Republic of Tanzania Gender-Based Violence and Violence Against Children," Soc Sci Med. 2011;152:40.

43. Higgins DJ, McCabe MP. Multiple forms of child abuse and neglect: adult retrospective reports. Aggression Violent Behav Rev J. 2001;6:547-78.

44. Mogaddam M, Kamal I, Merdad L, Alamoudi N, Meligy OE, et al. Prevalence of child abuse in Saudi Arabia from 2000 to 2015: a review of the literature. J Oral Hyg Health. 2015;3:189.

45. D. Control. No. 20: Adverse Childhood Experiences in NSCAW. 1997; 1997(20):1-6.

46. E. Franck, R. D. E. Raedt, C. Barbez, and Y. Rosseel, "Psychometric properties of the dutch Rosenberg self-esteem scale," pp. 25-35, 2008.

47. Bernstein DP, Fink L. Childhood Trauma Questionnaire: A retrospective selfreport manual. Psychol Corp. 1998;28:889-904.

48. Wade R, Shea JA, Rubin D, Wood J. Adverse childhood experiences of low-income urban youth. Pediatrics. 2014;134(1):e13-20.

49. Ports KA, Ford DC, Merrick MT. Adverse childhood experiences and sexual victimization in adulthood. Child Abuse Negl. 2015;134(1):e13-e20.

50. Paivio SC, Cramer KM. Factor structure and reliability of the childhood trauma questionnaire in a Canadian undergraduate student sample. Child Abus Neglect. 2004;28:889-904.

51. Bernstein J, P D, Fink L, Handelsman L, Foote J, Lovejoy M, Wenzel K, Sapareto $E$, Ruggeriero. Initial reliability and validity of a new retrospective measure of child abuse and neglect. Am J Psychiatry. 1994;151:1132-6.

52. Slade T, Burgess P, Grove R. Kessler psychological distress scale: normative data from the 2007 Australian National Survey of mental health and wellbeing. Aust N Z J Psychiatry. 2011;45:308-16.

53. Weiss JA, Waechter R, Wekerle C. The impact of emotional abuse on psychological distress among child protective services-involved adolescents with borderline-to-mild intellectual disability; 2011. p. 142-59.

54. Egeland B. Child Abuse \& Neglect Taking stock : Childhood emotional maltreatment and developmental psychopathology. Child Abuse Negl. 2009;33:22-6.

55. Bernstein DP, et al. Initial reliability and validity of a new retrospective measure of child abuse and neglect. Am J Psychiatry. 1994;151(8):1132-6.

56. Herbison GP. The long-term impact of the physical, emotional, and sexual abuse of children : a community study. Child Abuse Negl. 1996; 20(I):7-21.

57. Trickett PK, Kim K, Prindle J. Child Abuse \& Neglect Variations in emotional abuse experiences among multiply maltreated young adolescents and relations with developmental outcomes. Child Abuse Negl. 2011;35(10):876-86.

58. Van Der Kooij IW, Nieuwendam J, Bipat S, Boer F, Lindauer RJL, Graafsma TLG. Child abuse \& neglect a national study on the prevalence of child abuse and neglect in Suriname. Child Abuse Negl. 2015:47:153-61. 
59. Lansford JE, Dodge KA, Pettit GS, Bates JE, Crozier J, Kaplow J. A 12-year prospective study of the long-term effects of early child physical maltreatment on psychological, behavioral, and academic problems in adolescence. Arch Pediatr Adolesc Med. Aug. 2002;156(8):824-30.

60. Lowell A, Renk K, Adgate AH. The role of attachment in the relationship between child maltreatment and later emotional and behavioral functioning. Child Abuse Negl. 2014;38(9):1436-49.

61. Heim C, Nemeroff CB. The role of childhood trauma in the neurobiology of mood and anxiety disorders: preclinical and clinical studies. Biol Psychiatry. 2001;49(12):1023-39.

62. Toda $\mathrm{H}$, et al. The structural equation analysis of childhood abuse, adult stressful life events, and temperaments in major depressive disorders and their influence on refractoriness; 2015. p. 2079-90.

Ready to submit your research? Choose BMC and benefit from:

- fast, convenient online submission

- thorough peer review by experienced researchers in your field

- rapid publication on acceptance

- support for research data, including large and complex data types

- gold Open Access which fosters wider collaboration and increased citations

- maximum visibility for your research: over $100 \mathrm{M}$ website views per year

At BMC, research is always in progress.

Learn more biomedcentral.com/submissions 